\title{
Cross-sectional study to identify staphylococcal species isolated from teat and inguinal skin of different-aged dairy heifers
}

\author{
P. R. F. Adkins, ${ }^{*}$ S. Dufour,† J. N. Spain,ł M. J. Calcutt,§ T. J. Reilly,§\# G. C. Stewart,§ll and J. R. Middleton* \\ ${ }^{*}$ Department of Veterinary Medicine and Surgery, University of Missouri, Columbia 65211 \\ †Department of Pathology and Microbiology, University of Montreal, Quebec, Canada J2S 2M2 \\ ‡Department of Animal Science, \\ §Department of Veterinary Pathobiology, \\ \#Veterinary Medical Diagnostic Laboratory, Department of Veterinary Pathobiology, and \\ IIBond Life Sciences Center, University of Missouri, Columbia 65211
}

\begin{abstract}
The purpose of this study was to describe the prevalence and distribution of staphylococcal species on the teat and inguinal skin of dairy heifers across the various stages of the heifer life cycle. The cross-sectional study included 106 Holstein heifers with an age range of $0 \mathrm{~d}$ to $27 \mathrm{mo}$ that were selected from 11 different groups, based on housing type and age, on a single dairy operation. A composite swabbing sample including all 4 teats and a second composite sample including both inguinal regions of each heifer were collected using gas-sterilized electrostatic dusters (Swiffers; Procter and Gamble, Cincinnati, OH). Swabbing samples were mixed with $10 \mathrm{~mL}$ of sterile saline, agitated, and cultured on mannitol salt agar plates. At $24 \mathrm{~h}$, plates were read and up to 10 staphylococcal colonies were saved for further analysis. Staphylococcal isolates were speciated using matrix-assisted laser desorption/ionization time-of-flight mass spectrometry or PCR amplification and partial sequencing of $r p o B$ or tuf. The prevalence of staphylococci was compared between the inguinal and teat regions using the chi-squared or Fisher's exact test, as applicable. Logistic regression models were used to investigate the relationship between a heifer's age (treated as a quantitative continuous variable) and the probability of isolating a given staphylococcal species from a given body site (inguinal region or teats). Overall, the most common species identified were Staphylococcus haemolyticus followed by Staphylococcus chromogenes, Staphylococcus xylosus, Staphylococcus devriesei, and Staphylococcus sciuri. Staphylococcus aureus was more prevalent on the teat than in the inguinal region, whereas Staphylococcus arlettae was more prevalent in the inguinal region than on the teat. All
\end{abstract}

Received October 10, 2017.

Accepted December 13, 2017.

${ }^{1}$ Corresponding author: middletonjr@missouri.edu other staphylococcal species were as likely to be found on the teat skin as the inguinal region skin. Isolation from the inguinal and teat skin was associated with age for Staphylococcus agnetis, S. chromogenes, S. devriesei, Staphylococcus equorum, S. haemolyticus, Staphylococcus lentus, S. sciuri, Staphylococcus vitulinus, and $S$. xylosus. The probability of finding $S$. chromogenes and $S$. agnetis on the teat and inguinal region increased with age, whereas the probability of $S$. devriesei and $S$. haemolyticus decreased with age. This study provides further insight into the ecology of staphylococcal species involved in heifer mastitis.

Key words: staphylococci, body site, heifer, matrixassisted laser desorption/ionization time-of-flight mass spectrometry

\section{INTRODUCTION}

Non-aureus Staphylococcus (NAS) species are the most common cause of subclinical mastitis in dairy heifers around the time of parturition (Fox, 2009; De Vliegher et al., 2012). The true effect of NAS IMI is still under debate, with descriptions ranging from a protective effect against IMI with other mastitis pathogens to an association with mild clinical mastitis (Taponen et al., 2006; Piepers et al., 2013). Some of the variability in the effect of NAS on the mammary gland may be associated with species differences. Recent research using molecular identification methods has demonstrated diversity among NAS species that can be found on the dairy farm as well as differences between species with regard to IMI, associated mammary inflammation, persistence of IMI, and ecological niches on and off the cow (Piessens et al., 2011; Supré et al., 2011; De Visscher et al., 2014; Fry et al., 2014). Staphylococci have been found in abundance in various extramammary sites (defined as any site not inside the mammary gland) including environmental sites such as floor samples, air samples, and used bedding samples as well as bovine 
body sites including the perineum, udder skin, and teat skin (Taponen et al., 2008; Piessens et al., 2011; De Visscher et al., 2016b; Adkins et al., 2018).

With regard to the microbial population of body sites, the teat end has been the most thoroughly investigated (Braem et al., 2012, 2013; De Visscher et al., 2016b). The bacteria identified on the skin of the teat end include 4 bacterial phyla: Firmicutes, Actinobacteria, Proteobacteria, and Bacteroidetes (Braem et al., 2012). The most frequently isolated genus of bacteria on the teat end is Staphylococcus (Braem et al., 2013). At the species level, Staphylococcus chromogenes, Staphylococcus haemolyticus, Staphylococcus devriesei, and Staphylococcus equorum have been the predominant NAS species identified at the teat ends of pregnant heifers (De Visscher et al., 2016b). Identification of some staphylococcal species on the teat end has been found to be associated with IMI. Specifically, finding $S$. chromogenes on the teat skin of late-term heifers has been shown to significantly increase the odds of $S$. chromogenes IMI around the time of parturition (De Visscher et al., 2016a; Adkins et al., 2018). This finding has also been demonstrated for other host-adapted staphylococcal species, specifically Staphylococcus aureus (Roberson et al., 1994). Furthermore, in one study, $44 \%$ of all heifers with a $S$. chromogenes IMI around the time of parturition had the same strain of S. chromogenes isolated from a body site, with many originating from the teat skin (Adkins et al., 2018). Although $S$. chromogenes IMI has been linked to elevated milk SCC and persistent IMI (Supré et al., 2011; Fry et al., 2014), isolation of $S$. chromogenes from the prepartum teat end has been associated with an SCC of $<200,000$ cells / $\mathrm{mL}$ and may protect against IMI in early lactation (De Vliegher et al., 2003).

Few studies have looked at isolation of staphylococcal species from other body sites besides the teat end. One study, in which extramammary sites of lactating cows were evaluated, including the udder skin, teat ends, perineum, and streak canal, found S. equorum, Staphylococcus sciuri, Staphylococcus saprophyticus, and Staphylococcus xylosus to be the predominant extramammary species (Taponen et al., 2008). In periparturient heifers, the teat skin, inguinal skin, muzzle, and perineum were evaluated and $S$. chromogenes, $S$. xylosus, S. haemolyticus, S. sciuri, and S. devriesei were found to be the predominant extramammary species (Adkins et al., 2018). Another study used phenotypic speciation methods to evaluate NAS species isolated from different-aged heifers' nares, hair coat, vagina, teat skin, and streak canal and found that S. xylosus, S. chromogenes, Staphylococcus warneri, and S. sciuri were the predominant species (White et al., 1989).
Further, as heifers' age increased, the recovery of $S$. xylosus and $S$. sciuri decreased, whereas recovery of $S$. chromogenes and $S$. warneri increased (White et al., 1989). When specifically investigating $S$. chromogenes on heifers, De Vliegher et al. (2003) found that the chance of isolating the organism from at least 1 teat end increased significantly with age.

Changes in populations of staphylococcal species isolated from body sites as heifers age have not been examined using currently available molecular speciation methods. Previously used phenotypic identification methods were based on bacterial metabolic activity and morphologic features, which can be affected by culture conditions, subculturing, and storage (Sauer and Kliem, 2010). Also, interpretation of phenotypic tests can be subjective (Carretto et al., 2005). Therefore, it has been recommended that phenotypic speciation methods be replaced by molecular speciation methods when conducting studies on the epidemiology and ecology of NAS that cause bovine mastitis (Vanderhaeghen et al., 2015). Additionally, since the White et al. (1989) study, several new staphylococcal species have been named that have been isolated from dairy cattle or their environment, including Staphylococcus nepalensis (Spergser et al., 2003; Zadoks and Watts, 2009), S. devriesei (Supré et al., 2010), and Staphylococcus agnetis (Taponen et al., 2012). Furthermore, although the isolation of staphylococcal species from teat and inguinal skin in periparturient heifers has been recently described (Adkins et al., 2018), the relationship between the isolation of staphylococcal species on the teat skin and inguinal skin and heifer age has not been fully examined. Previous research investigating the isolation of $S$. aureus from body sites has specifically considered teat skin separately from the sides of the udder, and no $S$. aureus was found on udder sides (Matos et al., 1991). However, isolation of staphylococcal species from the inguinal region has not been evaluated among various heifer age groups. Therefore, the purpose of this study was to describe the prevalence and distribution of staphylococcal species on the teat and inguinal skin of dairy heifers by examining a cross-section of animals in various stages of the heifer life cycle on 1 farm.

\section{MATERIALS AND METHODS}

\section{Herd and Heifer Selection}

A cross-sectional study of Holstein heifers was conducted at the University of Missouri dairy research farm located near Columbia, Missouri, in the central part of the state, between March and June 2015. At the time of sampling, the farm milked a total of 160 
Holstein and 24 Guernsey cows. During the sampling months, the Holstein herd had a geometric mean SCC of $211,000 \mathrm{cell} / \mathrm{mL}$ and an average 305 -d milk production of $11,767 \mathrm{~kg}$. All heifers $(\mathrm{n}=229)$ were raised on the farm. Calving occurred year round with the exception of a planned reduction in calving between July and September to minimize calving during peak heat and humidity in Missouri. This study was approved by the University of Missouri Animal Care and Use Committee.

Heifers aged $0 \mathrm{~d}$ to $821 \mathrm{~d}(27 \mathrm{mo})$ were selected from 11 different groups based on housing type and age (Table 1). Each of the groups was within an approximately 1 mile $(1.6 \mathrm{~km})$ radius on the farm. The sampling strategy was planned to include approximately $50 \%$ of the heifers on the farm, and the number of heifers to be sampled per group was preselected to include an approximately equal representation of animals in each housing type and age group (Table 1). The planned samples included a total of 120 heifers; the median number of planned samples per group was 10 , with a range of 6 to 15. Heifers within each group were randomly selected for sampling using a Microsoft Excel (Microsoft Corp., Redmond, WA) random number generator. Selected heifers were sampled only once.

\section{Sampling Procedure}

Heifers were restrained, and body site swabbing samples including a composite sample of the skin surface of all 4 teats and a second composite sample combining the skin surface of both inguinal regions of each heifer were collected. Prior to sample collection, visible debris was removed using a dry disposable towel. Swabbing samples were collected using gas-sterilized electrostatic dusters (Swiffers; Procter and Gamble, Cincinnati, OH; Hoet et al., 2011; van Balen et al., 2013). Gloves were worn at all times and were changed between each sample collected. All swabbing samples were placed in sterile 710-mL whirl pack bags (Nasco, Fort Atkinson, WI), chilled on ice, and transported to the laboratory, where they were processed the same day.

\section{Laboratory Procedures}

Swabbing samples were mixed with $10 \mathrm{~mL}$ of sterile saline in the original whirl pack bag and agitated. Then, $50 \mu \mathrm{L}$ of the resultant solution was plated on mannitol salt agar (MSA; Remel, Lenexa, KS), spread with a sterile spreader bar, and incubated at $37^{\circ} \mathrm{C}$ for $24 \mathrm{~h}$. At $24 \mathrm{~h}$, MSA plates were visually interpreted and up to 10 staphylococcal colonies, including at least 1 of each morphologically distinct colony type, were subcultured onto Columbia blood agar (CBA; Remel), incubated at $37^{\circ} \mathrm{C}$ for $24 \mathrm{~h}$, and then stored in phosphate buffered glycerol at $-80^{\circ} \mathrm{C}$ until further processing.

Staphylococcal isolates were speciated using matrixassisted laser desorption/ionization time-of-flight (MALDI-TOF) MS (Tomazi et al., 2014; Cameron et al., 2017, 2018). Briefly, isolates were grown from storage medium on $\mathrm{CBA}$ at $37^{\circ} \mathrm{C}$ for 18 to $24 \mathrm{~h}$, and an isolated colony was used to prepare the MALDITOF target plate using the plate extraction method. One colony of each isolate was spotted on the plate in duplicate. Spots were overlaid with $1 \mu \mathrm{L}$ of $70 \%$ formic acid. Once dried, each spot was overlaid with 1 $\mu \mathrm{L}$ of matrix solution, consisting of $\alpha$-cyano-4-hydroxy cinnamic acid diluted in a solution of $50 \%$ acetonitrile and $2.5 \%$ trifluoroacetic acid. Bacterial test standard (Bruker Daltonics Inc., Billerica, MA) was used to calibrate the instrument before running test samples. Samples were analyzed on a MALDI-TOF mass spectrometer (Microflex; Bruker Daltonics Inc.) using proprietary software (Flex Control; Bruker Daltonics Inc.). Peaks produced by each isolate were compared with entries in the database (Biotyper Database; Bruker Daltonics Inc.) and the University of Missouri custom database [which included bovine reference isolates of

Table 1. Housing characteristics for the different groups $(n=11)$ of heifers included in the study

\begin{tabular}{|c|c|c|c|}
\hline Group & Age & Grouping characteristics & Bedding type \\
\hline Newborn calves & $0-3 \mathrm{~d}$ & Individually housed in maternity barn & Straw on concrete \\
\hline Hutch calves & $1 \mathrm{~d}-2.4 \mathrm{mo}$ & Individually housed & Straw-covered rock \\
\hline Weaned heifers & $2.6-5.6 \mathrm{mo}$ & $\begin{array}{l}\text { Superhutch: } 5 \text { groups, } 6-7 \text { heifers/ } \\
\text { group }\end{array}$ & Pasture and shelter with straw \\
\hline Pasture 1 & $5.6-6.5 \mathrm{mo}$ & 1 group & Pasture and shelter with manure pack \\
\hline Pasture 2 & $6.5-8.9 \mathrm{mo}$ & 1 group & Pasture and shelter with manure pack \\
\hline Pasture 3 & $9.8-13.6 \mathrm{mo}$ & 1 group & Pasture and shelter with manure pack \\
\hline Pasture 4 & $10.8-16 \mathrm{mo}$ & 1 group & Pasture only \\
\hline Breeding-age heifers & $14.9-18 \mathrm{mo}$ & 1 group & Freestalls with sand bedding \\
\hline Early-gestation heifers & $15.7-19.2 \mathrm{mo}$ & 1 group & Pasture and shelter with manure pack \\
\hline Confirmed-pregnant heifers & $15.3-28 \mathrm{mo}$ & 1 group & Pasture and shelter with manure pack \\
\hline Late-gestation heifers & $21.7-27 \mathrm{mo}$ & 1 group, mixed with cows & Pasture and sand-bedded freestalls \\
\hline
\end{tabular}


S. devriesei $(\mathrm{n}=1), S$. agnetis $(\mathrm{n}=1)$, and $S$. haemolyticus $(\mathrm{n}=1)$ ] using the standard parameters of the pattern-matching algorithm. The 3 species in the custom database were added because they were absent from the Bruker database (S. devriesei and S. agnetis) or because of low typeability relative to the reference strains in the Bruker database (S. haemolyticus; Adkins et al., 2018). Custom database entries were made following the manufacturer's recommended methods in which 100 known isolates of each species added to the custom database were run against the reference isolate in the custom database to validate that the reference isolate accurately identified each of the 100 known isolates. Species identification cut-off values were applied according to the manufacturer's instructions in which a score of $\geq 2$ indicated a species-level identification. Any score $<2$ was classified as inconclusive for species identification.

Any isolate that was not conclusively identified by MALDI-TOF was speciated using PCR amplification and sequencing of a portion of rpoB or tuf. Briefly, isolates were subcultured from storage medium on CBA at $37^{\circ} \mathrm{C}$ for $24 \mathrm{~h}$, and a single colony was inoculated into $100 \mu \mathrm{L}$ of $1 \times$ Tris-EDTA (Promega, Madison, WI) for lysate preparation. Standard PCR was performed to amplify a portion of rpoB (Drancourt and Raoult, 2002) or tuf (Hwang et al., 2011). The resultant PCR products were purified using a commercial kit (Invitrogen, Carlsbad, CA) and submitted to the University of Missouri DNA Core Facility for sequencing. Sequences were compared with the GenBank database using the publicly available nucleotide-BLAST algorithm (www .ncbi.nlm.nih.gov). For rpo $B$ analysis, species identity was confirmed when the sequence was $\geq 97 \%$ identical to a single staphylococcal species in the GenBank database (Heikens et al., 2005; Mellmann et al., 2006). For tuf analysis, species were confirmed when sequence identity was $\geq 98.0 \%$ identical to a single staphylococcal species and there was $>0.8 \%$ separation between identified species (Hwang et al., 2011). All isolates identified as $S$. agnetis or $S$. hyicus by MALDI-TOF were speciated using the aroD multiplex PCR (Adkins et al., 2017) because MALDI-TOF cannot differentiate these 2 species (Adkins et al., 2018; Cameron et al., 2018). All isolates that could not be speciated by MALDI-TOF, housekeeping gene sequencing ( $r p o B$ or tuf), or the aroD multiplex PCR were designated as unidentified staphylococci.

\section{Statistical Analyses}

The prevalence of the various staphylococcal species identified was cross-tabulated by body site. To investi- gate whether staphylococcal prevalence was different between the inguinal and teat region, Chi-squared tests were conducted. Whenever a cell with an expected frequency $<5$ was observed, the Fisher's exact test was used instead.

Logistic regression models were used to investigate the relationship between heifers' age (treated as a quantitative continuous variable) and the probability of isolating a given staphylococcal species from a given body site (inguinal region or teat). In these models, outcome was presence or absence of a given staphylococcal species on a given body site; one logistic model was, therefore, used for each staphylococcal species (provided that the number of isolates observed was sufficient to achieve convergence of the model), and analyses were conducted independently for the inguinal and teat regions. To fully model the relationship between $\log$ odds of staphylococcal species isolation and heifers' age, the relationship was always initially modeled using polynomial age terms (i.e., age, age $^{2}$, and age $^{3}$ ). Whenever the coefficient of the age ${ }^{3}$ term yielded a $P$ value $>0.05$, the relationship was deemed to have $\leq 1$ inflexion point and the age ${ }^{3}$ term was removed from the model. Then, if the coefficient of the age $^{2}$ term yielded a $P$-value $>0.05$, the relationship was deemed to be linear and the age ${ }^{2}$ term was also removed. If the coefficient for age also yielded, after removal of the age ${ }^{3}$ and age $^{2}$ terms, a $P$-value $>0.05$, then the log odds of body site isolation were deemed to be constant across different heifer age groups. To avoid collinearity, all age terms were centered around $365 \mathrm{~d}$ and divided by 30 so that the odds ratio reported would indicate relative increase or decrease in odds of staphylococcal species isolation for each additional $30 \mathrm{~d}$ of age.

\section{RESULTS}

The total number of heifers sampled was 106, which was $46 \%$ of the total heifer population on the farm at the time of the study. The median number of heifers sampled per group was 10 (range: 3-15). Less than the planned number of animals was sampled in some groups due to fewer total numbers of heifers than expected being available in those groups at the time of sampling. Classifying the heifers based on age, $19 \%$ $(20 / 106)$ were $0 \mathrm{~d}$ to $2 \mathrm{mo}, 15 \%(16 / 106)$ were 2 to 6 mo, $24 \%(25 / 106)$ were 6 to 12 mo, $22 \%(23 / 106)$ were 12 to $18 \mathrm{mo}$, and $21 \%(22 / 106)$ were $>18$ mo.

A total of 2,044 staphylococcal isolates from 212 body sites were evaluated. At least 1 staphylococcal isolate was identified from all 212 body sites. The MALDITOF mass spectrometer was able to identify $90.3 \%$ $(1,845 / 2,044)$ of the isolates using the aforementioned 
diagnostic threshold, and 9.7\% (199/2,044) could not be identified with this method. Five isolates $(0.7 \%)$ could not be identified to the species level using any of the speciation methods described above. Due to replication of a single species on the same body site, 1,361 replicates from the original 2,044 body site isolations were eliminated from the data set for the purpose of analysis, leaving 683 occurrences of staphylococcal species isolation from a body site. Of the 683 occurrences, 344 were from the inguinal region, with the median number of species per inguinal sample being 3 (range: 1-6), and 339 were from the teat skin, with the median number of species per teat skin sample also being 3 (range: 1-7). A total of 17 different staphylococcal species were identified (Table 2).

Assessing species distribution based on body site location found few differences between body sites (Table 2). Staphylococcus aureus was more prevalent on the teats than in the inguinal region $(P<0.01)$. Staphylococcus arlettae was more prevalent in the inguinal region than on the teats $(P=0.04)$. All other staphylococcal species were as likely to be found on the teat skin as on the inguinal region skin. Staphylococcus cohnii, Staphylococcus epidermidis, and Staphylococcus succinus were each identified only once and were found only on the teat skin.
Overall, the most common species identified were $S$. haemolyticus and S. chromogenes, followed by $S$. xylosus, $S$. devriesei, and $S$. sciuri (Table 2). Less commonly identified species included S. equorum, Staphylococcus lentus, Staphylococcus vitulinus, S. agnetis, S. arlettae, $S$. aureus, Staphylococcus simulans, S. saprophyticus, and S. nepalensis. The proportion of heifers of a given age in which a given species was isolated varied for both the inguinal region (Table 3) and teat skin (Table 4). The most commonly identified species in the inguinal region of heifers $<2$ mo of age ( $\mathrm{n}=20$ heifers) were $S$. xylosus, $S$. lentus, $S$. sciuri, and $S$. vitulinus, whereas the most commonly identified species on the teat skin were $S$. xylosus, S. sciuri, and S. equorum. For heifers 2 to 6 mo of age $(\mathrm{n}=16)$, the most commonly identified species in the inguinal region were $S$. haemolyticus, S. sciuri, and $S$. devriesei, and the most commonly identified species on the teat skin were $S$. haemolyticus, $S$. sciuri, and S. xylosus. For heifers 6 to 12 mo of age $(\mathrm{n}=25)$, the most commonly identified species in the inguinal region were S. haemolyticus, S. chromogenes, and S. xylosus, whereas the most commonly identified species on the teat skin were $S$. haemolyticus, $S$. chromogenes, and $S$. devriesei. For heifers 12 to 18 mo of age $(\mathrm{n}=23)$, the most commonly identified species in the inguinal region were S. haemolyticus, S. chromogenes, S. devriesei, and

Table 2. Proportion of staphylococcal isolates, organized by most prevalent to least prevalent species, isolated from the inguinal or teat skin of heifers $(n=106)$ aged 1 d to 27 mo

\begin{tabular}{|c|c|c|c|c|}
\hline \multirow[b]{2}{*}{ Staphylococcal species } & \multirow[b]{2}{*}{ No. (\%) of isolates } & \multicolumn{2}{|c|}{ No. $(\%)$ of heifers } & \multirow[b]{2}{*}{$P$-value ${ }^{1}$} \\
\hline & & Inguinal & Teat & \\
\hline S. haemolyticus & $164(24.0)$ & $83(78.3)$ & $81(76.4)$ & 0.74 \\
\hline S. chromogenes & $154(22.5)$ & $78(73.6)$ & $76(71.7)$ & 0.76 \\
\hline S. xylosus & $84(12.3)$ & $43(40.6)$ & $40(37.7)$ & 0.57 \\
\hline S. devriesei & $59(8.6)$ & $28(26.4)$ & $31(29.3)$ & 0.65 \\
\hline S. sciuri & $57(8.3)$ & $28(26.4)$ & $29(27.4)$ & 0.88 \\
\hline S. equorum & $33(4.8)$ & $14(13.2)$ & $19(17.9)$ & 0.34 \\
\hline S. lentus & $32(4.7)$ & $17(16.0)$ & $15(14.2)$ & 0.70 \\
\hline S. vitulinus & $29(4.2)$ & $14(13.2)$ & $14(13.2)$ & 0.84 \\
\hline S. agnetis & $25(3.7)$ & $15(14.2)$ & $10(9.4)$ & 0.29 \\
\hline S. arlettae & $16(2.3)$ & $11(10.4)$ & $4(3.8)$ & 0.04 \\
\hline S. aureus & $11(1.6)$ & $1(0.9)$ & $10(9.4)$ & $<0.01$ \\
\hline Unidentified staphylococci ${ }^{2}$ & $5(0.7)$ & $3(2.8)$ & $2(1.9)$ & $0.32^{3}$ \\
\hline S. saprophyticus & $4(0.6)$ & $1(0.9)$ & $3(2.8)$ & $0.25^{3}$ \\
\hline S. simulans & $4(0.6)$ & $3(2.8)$ & $1(0.9)$ & $0.25^{3}$ \\
\hline S. nepalensis & $3(0.4)$ & $2(1.9)$ & $1(0.9)$ & $0.37^{3}$ \\
\hline S. cohnii & $1(0.1)$ & $0(0.0)$ & $1(0.9)$ & $0.50^{3}$ \\
\hline S. epidermidis & $1(0.1)$ & $0(0.0)$ & $1(0.9)$ & $0.50^{3}$ \\
\hline S. succinus & $1(0.1)$ & $0(0.0)$ & $1(0.9)$ & $0.50^{3}$ \\
\hline
\end{tabular}

${ }^{1} P$-value for the chi-squared test (unless otherwise specified) testing the association between prevalence of a given staphylococcal species and body site.

${ }^{2}$ Isolates for which staphylococcal species was undetermined after matrix-assisted laser desorption/ionization time of flight, rpoB sequencing, tuf sequencing, and aroD multiplex PCR.

${ }^{3} P$-value for a Fisher's exact test testing the association between prevalence of a given staphylococcal species and body site. Fisher's exact test was used when expected frequency was $<5$ in $\geq 1$ cell. 
Table 3. Proportion of heifers $(\mathrm{n}=106)$ of a given age $(1 \mathrm{~d}-27 \mathrm{mo})$ in which various staphylococcal species were isolated from the inguinal region

\begin{tabular}{|c|c|c|c|c|c|}
\hline Item & \multicolumn{5}{|c|}{ No. (\%) of heifers } \\
\hline S. agnetis & $0(0.0)$ & $0(0.0)$ & $5(20.0)$ & $5(21.7)$ & $5(22.7)$ \\
\hline S. arlettae & $3(15.0)$ & $3(18.8)$ & $1(4.0)$ & $0(0.0)$ & $4(18.2)$ \\
\hline S. aureus & $0(0.0)$ & $0(0.0)$ & $0(0.0)$ & $0(0.0)$ & $1(4.6)$ \\
\hline S. chromogenes & $7(35.0)$ & $4(25.0)$ & $24(91.3)$ & $21(91.3)$ & $22(100)$ \\
\hline S. epidermidis & $0(0.0)$ & $0(0.0)$ & $0(0.0)$ & $0(0.0)$ & $0(0.0)$ \\
\hline S. equorum & $11(55.0)$ & $0(0.0)$ & $1(4.0)$ & $1(4.4)$ & $1(4.6)$ \\
\hline S. haemolyticus & $3(15.0)$ & $15(93.8)$ & $24(96.0)$ & $21(91.3)$ & $20(90.9)$ \\
\hline S. lentus & $13(65.0)$ & $3(18.8)$ & $1(4.0)$ & $0(0.0)$ & $0(0.0)$ \\
\hline S. nepalensis & $1(5.0)$ & $1(6.3)$ & $0(0.0)$ & $0(0.0)$ & $0(0.0)$ \\
\hline S. saprophyticus & $1(5.0)$ & $0(0.0)$ & $0(0.0)$ & $0(0.0)$ & $0(0.0)$ \\
\hline S. sciuri & $12(60.0)$ & $13(81.3)$ & $1(4.0)$ & $1(4.4)$ & $1(4.6)$ \\
\hline No. of heifers in a given age category & 20 & 16 & 25 & 23 & 22 \\
\hline
\end{tabular}

${ }^{1}$ Isolates for which staphylococcal species was undetermined after matrix-assisted laser desorption/ionization time of flight, rpo $B$ sequencing, tuf sequencing, and aroD multiplex PCR.

S. xylosus and on the teat skin were $S$. haemolyticus, S. chromogenes, and $S$. devriesei. For heifers $>18$ mo of age $(\mathrm{n}=22$ heifers), the most commonly identified species in the inguinal region were $S$. chromogenes, $S$. haemolyticus, S. devriesei, and S. xylosus, whereas the most commonly identified species on teat skin were $S$. chromogenes, S. haemolyticus, and S. devriesei.
Logistic regression models revealed that, for many of the species, isolation from the inguinal region and teat skin with a particular staphylococcal species was associated with age of the heifer (Tables 5 and 6 ; Figures 1 and 2). In the inguinal region, the probability of isolating $S$. agnetis, S. chromogenes, and $S$. xylosus increased with age, whereas the probability of

Table 4. Proportion of heifers $(\mathrm{n}=106)$ of a given age $(1 \mathrm{~d}-27 \mathrm{mo})$ in which various staphylococcal species were isolated from the teat skin

\begin{tabular}{|c|c|c|c|c|c|}
\hline Item & \multicolumn{5}{|c|}{ No. $(\%)$ of heifers } \\
\hline \multicolumn{6}{|l|}{ Staphylococcal species } \\
\hline S. arlettae & $1(5.0)$ & $0(0.0)$ & $1(4.0)$ & $1(4.4)$ & $1(4.6)$ \\
\hline S. aureus & $1(5.0)$ & $0(0.0)$ & $1(4.0)$ & $5(21.8)$ & $3(13.6)$ \\
\hline S. chromogenes & $8(40.0)$ & $2(12.5)$ & $25(100)$ & $21(91.3)$ & $20(90.9)$ \\
\hline S. equorum & $14(70.0)$ & $0(0.0)$ & $2(8.0)$ & $1(4.4)$ & $2(9.1)$ \\
\hline S. haemolyticus & $4(20.0)$ & $15(93.8)$ & $25(100)$ & $22(96.7)$ & $15(68.2)$ \\
\hline S. lentus & $9(45.0)$ & $3(18.8)$ & $2(8.0)$ & $0(0.0)$ & $1(4.6)$ \\
\hline S. nepalensis & $0(0.0)$ & $0(0.0)$ & $1(4.0)$ & $0(0.0)$ & $0(0.0)$ \\
\hline S. saprophyticus & $2(10.0)$ & $0(0.0)$ & $0(0.0)$ & $0(0.0)$ & $1(4.6)$ \\
\hline S. sciuri & $15(75.0)$ & $11(68.8)$ & $1(4.0)$ & $1(4.4)$ & $1(4.6)$ \\
\hline No. of heifers in a given age category & 20 & 16 & 25 & 23 & 22 \\
\hline
\end{tabular}

${ }^{1}$ Isolates for which staphylococcal species was undetermined after matrix-assisted laser desorption/ionization time of flight, rpo $B$ sequencing, tuf sequencing, and aroD multiplex PCR. 
isolating S. devriesei, S. equorum, S. haemolyticus, $S$. lentus, S. sciuri, and S. vitulinus decreased with age (Table 5; Figure 1). On the teat skin, the probability of isolating $S$. agnetis and $S$. chromogenes increased with age, whereas the probability of isolating $S$. devriesei, S. equorum, S. haemolyticus, S. lentus, S. sciuri, $S$. vitulinus, and $S$. xylosus decreased with age (Table 6; Figure 2). Staphylococcus xylosus was the only species that yielded conflicting results between sites, with an increase in the probability of isolation from the inguinal region as age increased and a decrease in the probability of isolation from the teat skin as age increased. The odds of isolating $S$. arlettae, S. cohnii, S. epidermidis, S. nepalensis, S. saprophyticus, S. simulans, or unidentified staphylococci from the teat or inguinal region was not affected by age of the heifer.

\section{DISCUSSION}

A very diverse population of staphylococcal species was found on the teat and inguinal region of heifers. This is in agreement with previous studies that have found staphylococcal species to be the most commonly isolated microbiota on the teat end of lactating cows
(Braem et al., 2013) and a diverse group of 24 different staphylococcal species on the teat ends of prepartum cows and heifers (De Visscher et al., 2016b). Interestingly, isolation of most staphylococcal species from the teat skin was as likely as isolation of the inguinal region with the exception of $S$. aureus and $S$. arlettae. Staphylococcus aureus was found to be more prevalent on the teat skin than in the inguinal region. This is in agreement with a previous study that did not identify any $S$. aureus on the udder sides of heifers but did find it in heifer teat skin samples (Matos et al., 1991). In contrast, Staphylococcus arlettae was found to be more prevalent in the inguinal region than on the teat skin in the current study. These data are similar to previous studies that found that $S$. arlettae was rarely identified among teat end samples (De Visscher et al., 2016b) and that $S$. arlettae was more commonly isolated from the udder skin than the teat end in lactating cows (Taponen et al., 2008).

The results of the present study showed that the staphylococcal populations change with heifer age. Host factors, such as hormonal changes and skin moisture content, can contribute to variability in the microbial flora of the skin (Grice and Segre, 2011).

Table 5. Unconditional associations between heifers' age and probability of isolating a given staphylococcal species from the inguinal region in 106 heifers from 1 farm and aged between $1 \mathrm{~d}$ and $27 \mathrm{mo}^{1}$

\begin{tabular}{|c|c|c|c|c|c|}
\hline Staphylococcal species & Parameter & $\beta$ & $\mathrm{SE}$ & Odds ratio & $95 \% \mathrm{CI}$ \\
\hline \multirow{3}{*}{ S. agnetis } & Intercept & -1.267 & 0.382 & - & - \\
\hline & Age & 0.187 & 0.074 & 1.2 & $1.0-1.4$ \\
\hline & $\mathrm{Age}^{2}$ & -0.514 & 0.248 & 0.60 & $0.37-0.97$ \\
\hline \multirow[t]{2}{*}{ S. chromogenes } & Intercept & 2.456 & 0.523 & - & - \\
\hline & Age & 0.295 & 0.064 & 1.3 & $1.2-1.5$ \\
\hline \multirow[t]{4}{*}{ S. devriesei } & Intercept & -0.324 & 0.321 & - & - \\
\hline & Age & -0.073 & 0.069 & 0.93 & $0.81-1.1$ \\
\hline & $\mathrm{Age}^{2}$ & -0.474 & 0.193 & 0.62 & $0.43-0.91$ \\
\hline & $\mathrm{Age}^{3}$ & 0.042 & 0.020 & 1.0 & $1.0-1.1$ \\
\hline \multirow[t]{3}{*}{ S. equorum } & Intercept & -3.684 & 0.728 & - & - \\
\hline & Age & -0.139 & 0.055 & 0.87 & $0.78-0.97$ \\
\hline & $\mathrm{Age}^{2}$ & 0.427 & 0.200 & 1.5 & $1.0-2.3$ \\
\hline \multirow[t]{4}{*}{ S. haemolyticus } & Intercept & 3.547 & 0.695 & - & - \\
\hline & Age & -0.216 & 0.118 & 0.81 & $0.64-1.0$ \\
\hline & $\mathrm{Age}^{2}$ & -0.772 & 0.227 & 0.46 & $0.30-0.72$ \\
\hline & $\mathrm{Age}^{3}$ & 0.083 & 0.030 & 1.1 & $1.0-1.2$ \\
\hline \multirow[t]{2}{*}{ S. lentus } & Intercept & -5.457 & 1.347 & - & - \\
\hline & Age & -0.523 & 0.135 & 0.59 & $0.46-0.77$ \\
\hline \multirow[t]{2}{*}{ S. sciuri } & Intercept & -2.130 & 0.447 & - & - \\
\hline & Age & -0.246 & 0.055 & 0.78 & $0.70-0.87$ \\
\hline \multirow[t]{3}{*}{ S. vitulinus } & Intercept & -59.496 & 27.485 & - & - \\
\hline & Age & -11.653 & 5.454 & $<0.01$ & $<0.01-0.38$ \\
\hline & $\mathrm{Age}^{2}$ & -16.780 & 8.000 & $<0.01$ & $<0.01-0.33$ \\
\hline \multirow[t]{4}{*}{ S. xylosus } & Intercept & -0.646 & 0.320 & - & - \\
\hline & Age & 0.121 & 0.072 & 1.1 & $0.98-1.3$ \\
\hline & $\mathrm{Age}^{2}$ & 0.057 & 0.158 & 1.1 & $0.78-1.4$ \\
\hline & $\mathrm{Age}^{3}$ & -0.056 & 0.022 & 0.95 & $0.91-0.99$ \\
\hline
\end{tabular}

${ }^{1}$ Effect of age (i.e., coefficient, SE, odds ratio, and 95\% CI) is reported for a 30-d increase in age. Intercept represents the $\log$ odds for a 365 -d-old heifer. Note that odds of isolating S. arlettae, S. nepalensis, S. saprophyticus, S. simulans, or other unidentified staphylococci from the inguinal region were not affected by age of the heifer; S. cohnii, S. epidermidis, and S. succinus were not retrieved from the inguinal region. 
Table 6. Unconditional associations between heifers' age and probability of isolating a given staphylococcal species from the teat region in 106 heifers from 1 farm and aged between $1 \mathrm{~d}$ and 27 mo

\begin{tabular}{llrlll}
\hline Staphylococcal species & Parameter & $\beta$ & SE & OR & $95 \%$ CI \\
\hline S. agnetis & Intercept & -2.388 & 0.385 & - & - \\
S. chromogenes & Age & 0.116 & 0.047 & 1.1 & $1.0-1.2$ \\
& Intercept & 2.063 & 0.417 & - & - \\
S. devriesei & Age & 0.145 & 0.039 & 1.2 & $1.1-1.2$ \\
& Age & -0.301 & 0.145 & 0.74 & $0.56-0.98$ \\
& Intercept & -0.476 & 0.324 & - & - \\
& Age & -0.174 & 0.072 & 0.84 & $0.73-0.97$ \\
S. equorum & Age & -0.334 & 0.178 & 0.72 & $0.51-0.97$ \\
& Age & 0.068 & 0.021 & 1.1 & $1.0-1.1$ \\
S. haemolyticus & Intercept & -3.521 & 0.651 & - & - \\
& Age & -0.113 & 0.037 & 0.89 & $0.83-0.96$ \\
& Age & 0.583 & 0.162 & 1.8 & $1.3-2.5$ \\
S. lentus & Intercept & 4.754 & 0.944 & - & - \\
S. sciuri & Age & -0.197 & 0.120 & 0.82 & $0.65-1.0$ \\
S. vitulinus & Age & -1.236 & 0.254 & 0.29 & $0.18-0.48$ \\
& Age & 0.058 & 0.027 & 1.1 & $1.0-1.1$ \\
S. xylosus & Intercept & -2.994 & 0.618 & - & - \\
& Age & -0.224 & 0.068 & 0.80 & $0.70-0.91$ \\
& Intercept & -2.303 & 0.491 & - & - \\
& Age & -0.284 & 0.061 & 0.75 & $0.67-0.85$ \\
& Intercept & -3.671 & 0.724 & - & - \\
& Age & -0.137 & 0.054 & 0.87 & $0.79-0.97$ \\
& Age & 0.427 & 0.198 & 1.5 & $1.0-2.3$ \\
& Intercept & -1.311 & 0.332 & - & - \\
& Age & -0.072 & 0.028 & 0.93 & $0.88-0.98$ \\
& Age & 0.315 & 0.113 & 1.4 & $1.1-1.7$ \\
\hline
\end{tabular}

${ }^{1}$ Effect of age (i.e., coefficient, SE, odds ratio, and 95\% CI) is reported for a 30-d increase in age. Intercept represents the $\log$ odds for a 365 -d-old heifer. Note that odds of isolating S. arlettae, S. cohnii, S. epidermidis, S. nepalensis, S. saprophyticus, S. simulans, or other unidentified staphylococci from the teat region were not affected by age of the heifer.

Additionally, environmental factors can play a role in establishment of skin bacterial populations (Grice and Segre, 2011). In the present study, some important staphylococcal species previously identified as host adapted and frequently reported to be associated with IMI, such as S. chromogenes, became more prevalent as heifers aged. This finding is in agreement with previous studies (White et al., 1989; De Vliegher et al., 2003). Conversely, species that have been previously determined to have an environmental origin, such as $S$. equorum and S. sciuri (Piessens et al., 2011), were more commonly isolated from the skin of younger heifers. The probability of isolating $S$. agnetis from teat skin and the inguinal region also increased with age in this study. Interestingly, this species was not identified in the inguinal region or on the teat skin of heifers $<6$ mo of age. Staphylococcus agnetis is a newly described species, and currently little is known about the ecology of this organism; however, it has been previously isolated from teat end samples (Taponen et al., 2012; De Visscher et al., 2016b). Previous work demonstrated that the probability of isolating $S$. xylosus and S. sciuri from the teat skin decreased as heifers aged (White et al., 1989). However, in the present study, isolating $S$. xylosus from the inguinal region was found to increase with heifer age. White et al. (1989) also found that isolating $S$. warneri was more likely as heifers aged, and this species was the most prevalent NAS isolated from the body sites of heifers on pasture. In the present study, S. warneri was not identified.

Overall, $S$. aureus was not frequently identified on udder skin in the present study. Staphylococcus aureus comprised only $1.6 \%$ of the total isolates. Previous studies have documented that 0 to $36.5 \%$ of heifers have $S$. aureus on their teat or udder skin (Matos et al., 1991; Roberson et al., 1994; Middleton et al., 2002; Anderson et al., 2012), with herd-to-herd variation being reported (Middleton et al., 2002). One possible explanation for the low prevalence of $S$. aureus isolated from teat and inguinal skin in the present study may be that the isolation methods were not selective for any specific staphylococcal species, whereas previous studies have used $S$. aureus-selective media (Roberson et al., 1994; Middleton et al., 2002). Using methods not specifically selective for $S$. aureus may have allowed heavier growth of other staphylococci that impaired the growth of less prevalent species in the sample, precluding identification of some species such as $S$. aureus. Most studies 

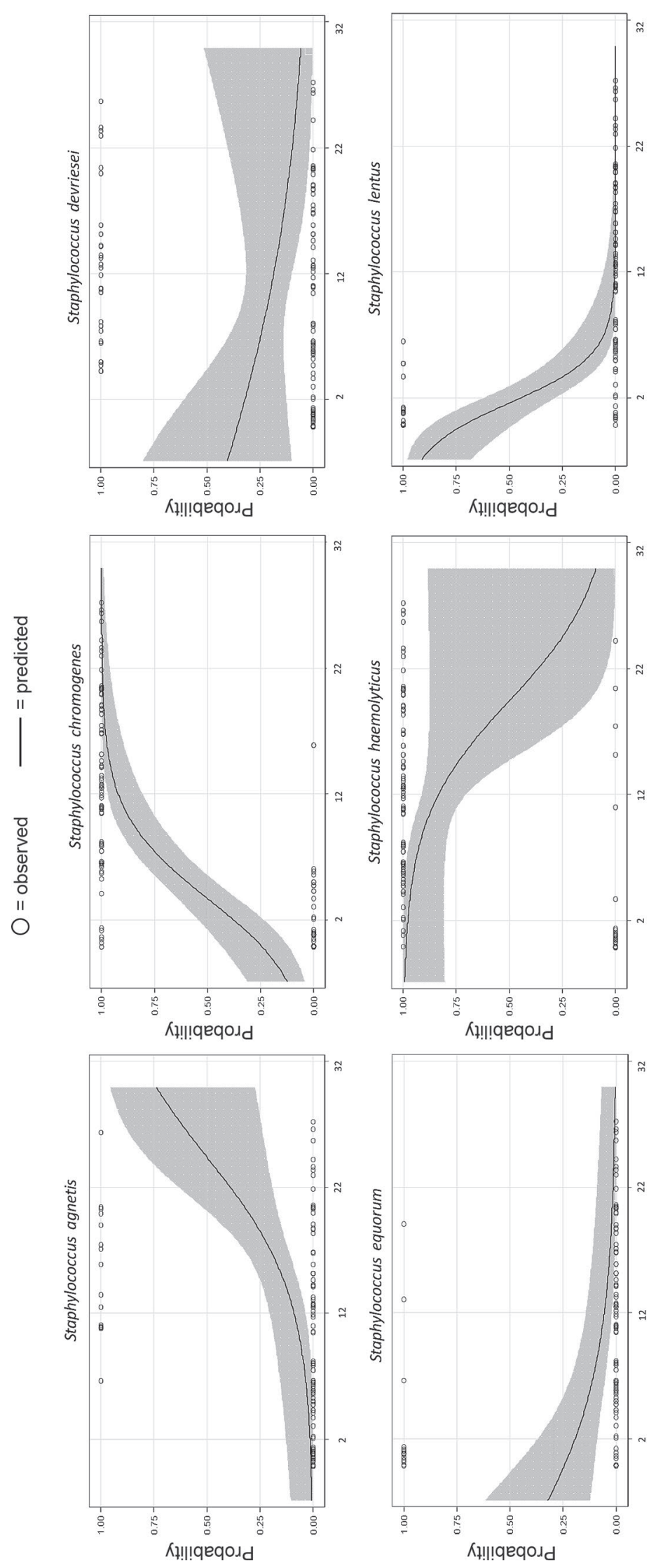

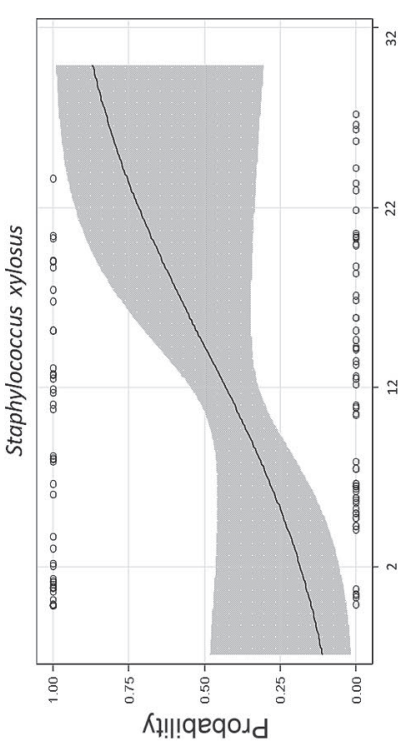

$\dot{0}$
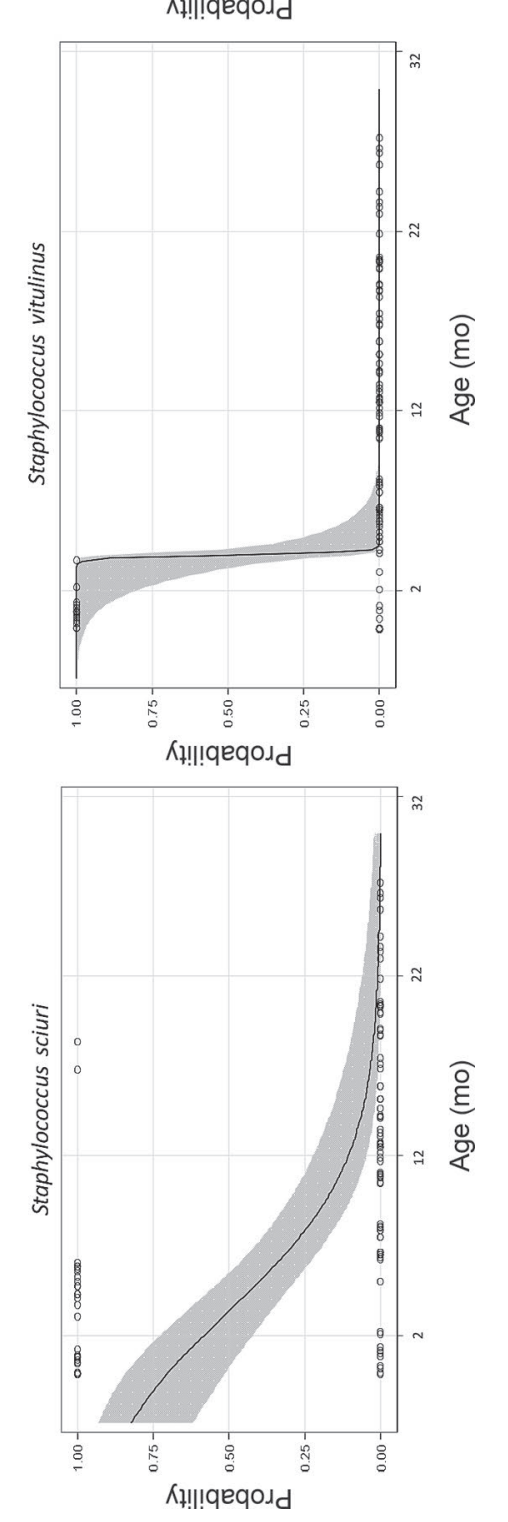

ชं

ํ. 잉

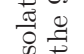

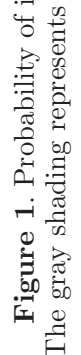

Journal of Dairy Science Vol. 101 No. 4, 2018 
ADKINS ET AL.
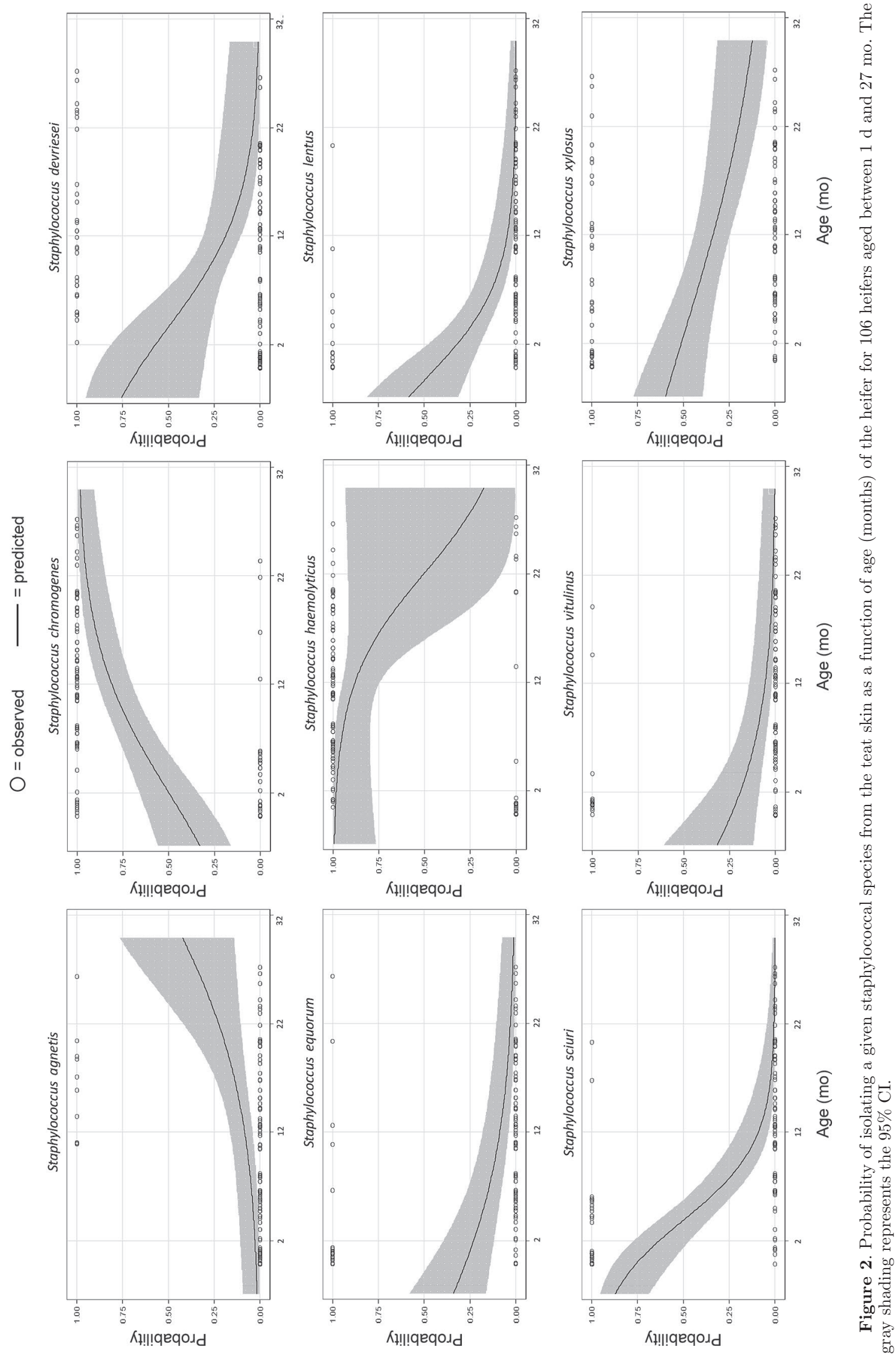
that have characterized $S$. aureus on body sites have used media such as Vogel and Johnson or Baird-Parker medium (Matos et al., 1991; Roberson et al., 1994). Although these selective media should allow growth of most staphylococcal species, at this time MSA is the only staphylococcal-specific medium that has been validated for growth and recovery of bovine-associated NAS (De Visscher et al., 2013). Although it is reported as a suitable method, the use of MSA for the isolation of NAS has its limitations. Previous work showed that the Staphylococcus auricularis type strain (ATCC 33753; American Type Culture Collection, Rockville, MD), Staphylococcus caseolyticus, and S. warneri failed to grow on MSA (White et al., 1988). A more recent study found that the $S$. auricularis type strain and $S$. warneri would grow on MSA; however, some strains of S. equorum, Staphylococcus hominis, and Staphylococcus lugdunensis showed delayed growth of $48 \mathrm{~h}$ at $37^{\circ} \mathrm{C}$ (De Visscher et al., 2013). With the exception of $S$. equorum, none of the other NAS species that failed to grow or had slow growth on MSA in previous studies (White et al., 1988; De Visscher et al., 2013) were isolated in the present study. Hence, it cannot be ruled out that our failure to identify these species was due to culture conditions rather than their absence on teat or inguinal skin. No previously tested selective staphylococcal media have been found to support the growth of all Staphylococcus spp. (White et al., 1988). Columbia blood agar or other nonselective media would perhaps be the best choice to allow growth of all staphylococcal species; however, lack of selectivity allows overgrowth of a multitude of Gram-negative and Gram-positive bacteria, making isolation of individual staphylococcal colonies difficult.

A further limitation of the present study is that sampling was done on only 1 farm. On the farm of study, heifers were kept in certain housing types until a specific age. Therefore, it is impossible to separate the roles of changing housing environments from that of age and, thus, determine the influence of housing strategy on changes in isolation of staphylococci from body sites versus the influence of increasing age of the heifers. Previous studies have identified that different management practices between farms may affect NAS species IMI distribution (De Visscher et al., 2016a; Condas et al., 2017) and teat end colonization (De Visscher et al., 2016b). This factor may also affect the isolation of staphylococcal species from body sites of heifers. This same limitation has been noted in previous studies that have evaluated the presence of staphylococcal species on body sites (White et al., 1989; Taponen et al., 2008). Although the present study used only 1 farm and therefore the generalizability of the data might be questioned, several findings corroborate previous reports from Kentucky (White et al., 1989) and Belgium (De Vliegher et al., 2003; De Visscher et al., 2016b). For example, the finding that $S$. chromogenes, $S$. devriesei, and $S$. haemolyticus were the most commonly identified species on the teat skin of heifers $>18$ mo of age agrees with a recent study looking at the isolation of NAS species from the teat end in dry cows and late-gestation heifers on 13 commercial dairy farms in Belgium (De Visscher et al., 2016a). Also, the finding of very few $S$. epidermidis on teat and inguinal skin is corroborated by others who did not find S. epidermidis on prepartum heifer teat ends (De Visscher et al., 2016b). Overall, the study conducted in Kentucky (White et al., 1989) was very similar to the present study. Similar findings between the 2 studies include the finding that the probability of isolating $S$. xylosus and $S$. sciuri from the teat skin decreased as heifer age increased and the probability of isolating $S$. chromogenes from the teat skin increased as heifer age increased. Although there were some similar findings, one notable difference between the 2 studies is the difference in the diversity of species, as White et al. (1989) found a total of 10 different species, whereas the present study identified 17 different species. This difference is likely due to differences in speciation method; molecular methods were used in the present study, whereas phenotypic speciation was used in the White et al. (1989) study. Further, the number of named staphylococcal species has increased since 1989 (Becker et al., 2014). In 1990, 25 staphylococcal species had been named, whereas today approximately 47 species and 23 subspecies of staphylococci are recognized (Becker et al., 2014). Several of the more recently classified species were found to be prevalent in the current study, including $S$. agnetis, S. devriesei, and $S$. nepalensis. Additionally, a few isolates in this study could not be speciated using molecular methods. These isolates may represent new species that need to be characterized.

The use of electrostatic dusters for body site sampling is a novel method. Electrostatic dusters have been previously used to collect environmental surface samples to determine the prevalence of methicillinresistant S. aureus (Hoet et al., 2011; van Balen et al., 2013). Although the use of electrostatic dusters in this study yielded growth of multiple species of staphylococci from teat and udder skin, this technique was not specifically compared with traditional culture swabs to determine its overall effectiveness in detecting bacteria in this context. Future studies should likely be conducted to compare these methods. Additional future work will include assessing staphylococcal species on heifers of different age groups on several different farms 
using different housing management to help further the understanding of the ecology of these organisms and potentially identify specific environmental risk factors.

\section{CONCLUSIONS}

The most common staphylococcal species identified on the teat and inguinal skin from heifers of multiple age groups were $S$. haemolyticus, S. chromogenes, and S. xylosus. Species distribution based on body site location did not differ for most species except $S$. aureus and $S$. arlettae. The probability of isolating $S$. chromogenes and $S$. agnetis from the teat and inguinal skin increased with age, whereas the probability of $S$. devriesei, $S$. equorum, S. haemolyticus, S. lentus, S. sciuri, and $S$. vitulinus decreased with age. Staphylococcus xylosus was the only species identified to have different probabilities of isolation based on location, with the probability of isolation from the inguinal region increasing with age and the probability of isolation from the teat skin decreasing with age. This study provides further insight into the ecology of staphylococcal species that can be isolated from the mammary gland skin and have the potential to cause IMI and mastitis in dairy heifers. The role and effect of isolating staphylococcal species from the teat and inguinal skin of heifers of different age groups remains to be elucidated, and the relationship to IMI and mastitis is the subject of other studies.

\section{ACKNOWLEDGMENTS}

This project was partially funded by USDA National Institute of Food and Agriculture project no. AH249573975. The authors thank the University of Missouri (Columbia) students who helped with this project, including Grant Voelker, Rachel Webster, and Luiza Placheta. We also thank the University of Missouri farm staff for all their assistance, especially Eric Adkins and John Denbigh. S. Dufour is supported by a National Sciences and Engineering Research Council of Canada Discovery Grant (Ottawa, Ontario, Canada).

\section{REFERENCES}

Adkins, P. R. F., S. Dufour, J. N. Spain, M. J. Calcutt, T. J. Reilly, G. C. Stewart, and J. R. Middleton. 2018. Molecular characterization of non-aureus Staphylococcus spp. from heifer intramammary infections and body sites. J Dairy Sci. https//doi.org/10.3168/ jds.2017-13910.

Adkins, P. R. F., J. R. Middleton, M. J. Calcutt, G. C. Stewart, and L. K. Fox. 2017. Speciation and strain-typing of Staphylococcus agnetis and Staphylococcus hyicus isolated from bovine milk using a novel multiplex PCR and pulsed-field gel electrophoresis. J. Clin. Microbiol. 55:1778-1788.
Anderson, K. L., R. Lyman, K. Moury, D. Ray, D. W. Watson, and M. T. Correa. 2012. Molecular epidemiology of Staphylococcus aureus mastitis in dairy heifers. J. Dairy Sci. 95:4921-4930.

Becker, K., C. Heilmann, and G. Peters. 2014. Coagulase-negative staphylococci. Clin. Microbiol. Rev. 27:870-926.

Braem, G., S. De Vliegher, B. Verbist, M. Heyndrickx, F. Leroy, and L. De Vuyst. 2012. Culture-independent exploration of the teat apex microbiota of dairy cows reveals a wide bacterial species diversity. Vet. Microbiol. 157:383-390.

Braem, G., S. De Vliegher, B. Verbist, V. Piessens, E. Van Coillie, L. De Vuyst, and F. Leroy. 2013. Unraveling the microbiota of teat apices of clinically healthy lactating dairy cows, with special emphasis on coagulase-negative staphylococci. J. Dairy Sci. 96:1499-1510.

Cameron, M., H. W. Barkema, J. De Buck, S. De Vliegher, M. Chaffer, J. Lewis, and G. P. Keefe. 2017. Identification of bovine-associated coagulase-negative staphylococci by matrix-assisted laser desorption/ionization time-of-flight mass spectrometry using a direct transfer protocol. J. Dairy Sci. 100:2137-2147.

Cameron, M., J. Perry, J. R. Middleton, M. Chaffer, J. Lewis, and G. P. Keefe. 2018. Short communication: Evaluation of MALDI-TOF mass spectrometry and a custom reference spectra expanded database for the identification of bovine-associated coagulase-negative staphylococci. J. Dairy Sci. 101:590-595.

Carretto, E., D. Barbarini, I. Couto, D. De Vitis, P. Marone, J. Verhoef, H. De Lencastre, and S. Brisse. 2005. Identification of coagulase-negative staphylococci other than Staphylococcus epidermidis by automated ribotyping. Clin. Microbiol. Infect. 11:177-184.

Condas, L. A. Z., J. De Buck, D. B. Nobrega, D. A. Carson, S. Naushad, S. De Vliegher, R. N. Zadoks, J. R. Middleton, S. Dufour, J. P. Kastelic, and H. W. Barkema. 2017. Prevalence of non-aureus staphylococci species causing intramammary infections in Canadian dairy herds. J. Dairy Sci. 100:5592-5612.

De Visscher, A., F. Haesebrouck, S. Piepers, W. Vanderhaeghen, K. Supré, F. Leroy, E. Van Coillie, and S. De Vliegher. 2013. Assessment of the suitability of mannitol salt agar for growing bovineassociated coagulase-negative staphylococci and its use under field conditions. Res. Vet. Sci. 95:347-351.

De Visscher, A., S. Piepers, F. Haesebrouck, and S. De Vliegher. 2016a. Intramammary infection with coagulase-negative staphylococci at parturition: Species-specific prevalence, risk factors, and effect on udder health. J. Dairy Sci. 99:6457-6469.

De Visscher, A., S. Piepers, F. Haesebrouck, and S. De Vliegher 2016b. Teat apex colonization with coagulase-negative Staphylococcus species before parturition: Distribution and species-specific risk factors. J. Dairy Sci. 99:1427-1439.

De Visscher, A., K. Supré, F. Haesebrouck, R. N. Zadoks, V. Piessens, E. Van Coillie, S. Piepers, and S. De Vliegher. 2014. Further evidence for the existence of environmental and host-associated species of coagulase-negative staphylococci in dairy cattle. Vet. Microbiol. 172:466-474.

De Vliegher, S., L. K. Fox, S. Piepers, S. McDougall, and H. W. Barkema. 2012. Invited review: Mastitis in dairy heifers: Nature of the disease, potential impact, prevention, and control. J. Dairy Sci. 95:1025-1040

De Vliegher, S., H. Laevens, L. A. Devriese, G. Opsomer, J. L. Leroy, H. W. Barkema, and A. de Kruif. 2003. Prepartum teat apex colonization with Staphylococcus chromogenes in dairy heifers is associated with low somatic cell count in early lactation. Vet. Microbiol. 92:245-252.

Drancourt, M., and D. Raoult. 2002. rpoB gene sequence-based identification of Staphylococcus species. J. Clin. Microbiol. 40:1333-1338.

Fox, L. K. 2009. Prevalence, incidence and risk factors of heifer mastitis. Vet. Microbiol. 134:82-88.

Fry, P. R., J. R. Middleton, S. Dufour, J. Perry, D. Scholl, and I Dohoo. 2014. Association of coagulase-negative staphylococcal species, mammary quarter milk somatic cell count, and persistence of intramammary infection in dairy cattle. J. Dairy Sci 97:4876-4885. 
Grice, E. A., and J. A. Segre. 2011. The skin microbiome. Nat. Rev. Microbiol. 9:244-253.

Heikens, E., A. Fleer, A. Paauq, A. Florijn, and A. C. Fluit. 2005. Comparison of genotypic and phenotypic methods for species-level identification of clinical isolates of coagulase-negative staphylococci. J. Clin. Microbiol. 43:2286-2290.

Hoet, A. E., A. Johnson, R. C. Nava-Hoet, S. Bateman, A. Hillier, J. Dyce, W. A. Gebreyes, and T. E. Wittum. 2011. Environmental methicillin-resistant Staphylococcus aureus in a veterinary teaching hospital during a nonoutbreak period. Vector Borne Zoonotic Dis. 11:609-615.

Hwang, S. M., M. S. Kim, K. U. Park, J. Song, and E. C. Kim. 2011. Tuf gene sequence analysis has greater discriminatory power than $16 \mathrm{~S}$ rRNA sequence analysis in identification of clinical isolates of coagulase-negative staphylococci. J. Clin. Microbiol. 49:4142-4149.

Matos, J. S., D. G. White, R. J. Harmon, and B. E. Langlois. 1991. Isolation of Staphylococcus aureus from sites other than the lactating mammary gland. J. Dairy Sci. 74:1544-1549.

Mellmann, A., K. Becker, C. von Eiff, U. Keckevoet, P. Schumann, and D. Harmsen. 2006. Sequencing and staphylococci identification. Emerg. Infect. Dis. 12:333-336.

Middleton, J. R., L. K. Fox, J. M. Gay, J. W. Tyler, and T. E. Besser. 2002. Use of pulsed-field gel electrophoresis for detecting differences in Staphylococcus aureus strain populations between dairy herds with different cattle importation practices. Epidemiol. Infect. 129:387-395.

Piepers, S., Y. H. Schukken, P. Passchyn, and S. De Vliegher. 2013 The effect of intramammary infection with coagulase-negative staphylococci in early lactating heifers on milk yield throughout first lactation revisited. J. Dairy Sci. 96:5095-5105.

Piessens, V., E. Van Coillie, B. Verbist, K. Supré, G. Braem, A. Van Nuffel, L. De Vuyst, M. Heyndrickx, and S. De Vliegher. 2011. Distribution of coagulase-negative Staphylococcus species from milk and environment of dairy cows differs between herds. J. Dairy Sci. 94:2933-2944.

Roberson, J. R., L. K. Fox, D. D. Hancock, J. M. Gay, and T. E. Besser. 1994. Ecology of Staphylococcus aureus isolated from various sites on dairy farms. J. Dairy Sci. 77:3354-3364.

Sauer, S., and M. Kliem. 2010. Mass spectrometry tools for the classification and identification of bacteria. Nat. Rev. Microbiol. 8:74-82.

Spergser, J., M. Wieser, M. Taubel, R. A. Rossello-Mora, R. Rosengerten, and H. J. Busse. 2003. Staphylococcus nepalensis spp. nov., isolated from goats of the Himalayan region. Int. J. Syst. Evol. Microbiol. 53:2007-2011.

Supré, K., S. De Vliegher, I. Cleenwerck, K. Engelbeen, S. Van Trappen, S. Piepers, O. C. Sampimon, R. N. Zadoks, P. De Vos, and F.
Haesebrouck. 2010. Staphylococcus devriesei sp. nov., isolated from teat apices and milk of dairy cows. Int. J. Syst. Evol. Microbiol. 60:2739-2744

Supré, K., F. Haesebrouck, R. N. Zadoks, M. Vaneechoutte, S. Piepers, and S. De Vliegher. 2011. Some coagulase-negative Staphylococcus species affect udder health more than others. J. Dairy Sci. 94:2329-2340.

Taponen, S., J. Bjorkroth, and S. Pyörälä. 2008. Coagulase-negative staphylococci isolated from bovine extramammary sites and intramammary infections in a single dairy herd. J. Dairy Res. 75:422429

Taponen, S., H. Simojoki, M. Haveri, H. D. Larsen, and S. Pyörälä. 2006. Clinical characteristics and persistence of bovine mastitis caused by different species of coagulase-negative staphylococci identified with API or AFLP. Vet. Microbiol. 115:199-207.

Taponen, S., K. Supré, V. Piessens, E. Van Coillie, S. De Vliegher, and J. M. Koort. 2012. Staphylococcus agnetis sp. nov., a coagulasevariable species from bovine subclinical and mild clinical mastitis. Int. J. Syst. Evol. Microbiol. 62:61-65.

Tomazi, T. J. L. Goncalves, J. R. Barreiro, P. A. de Campos Braga, L. F. Prada e Silva, M. N. Eberlin, and M. V. dos Santos. 2014. Identification of coagulase-negative staphylococci from bovine intramammary infection by matrix-assisted laser desorption ionizationtime of flight mass spectrometry. J. Clin. Microbiol. 52:1658-1663.

van Balen, J., C. Kelley, R. C. Nava-Hoet, S. Bateman, A. Hillier, J. Dyce, T. E. Wittum, and A. E. Hoet. 2013. Presence, distribution, and molecular epidemiology of methicillin-resistant Staphylococcus aureus in a small animal teaching hospital: A year-long active surveillance targeting dogs and their environment. Vector Borne Zoonotic Dis. 13:299-311.

Vanderhaeghen, W., S. Piepers, F. Leroy, E. Van Coillie, F. Haesebrouck, and S. DeVliegher. 2015. Identification, typing, ecology and epidemiology of coagulase negative staphylococci associated with ruminants. Vet. J. 203:44-51.

White, D. G., R. J. Harmon, J. E. Matos, and B. E. Langlois. 1989. Isolation and identification of coagulase-negative Staphylococcus species from bovine body sites and streak canals of nulliparous heifers. J. Dairy Sci. 72:1886-1892.

White, D. G., J. S. Matos, R. J. Harmon, and B. E. Langlois. 1988. A comparison of six selective media for the enumeration and isolation of staphylococci. J. Food Prot. 51:685-690.

Zadoks, R. N., and J. L. Watts. 2009. Species identification of coagulase-negative staphylococci: Genotyping is superior to phenotype. Vet. Microbiol. 134:20-28. 